\title{
AMA
}

\section{Cia Espaço Preto}

"Ama" é livremente inspirada no texto "Além do Rio", do autor Agostinho Olavo, escrito em 1957. O autor conta a história Para conhecer mais sobre o trabalho da companhia, acesse: de Jinga, rainha nascida na Costa d'Ouro (GANA - Africa), através dos costumes e culturas de matriz africana, por meio das quais a saga da rainha é transcriada a partir do mito grego de Medea. Diante disso, Ama apresenta as Jingas contemporâneas e discute o mítico arquétipo de "Medea" no contexto periférico/ urbano, tendo como material de pesquisa memórias e histórias de mulheres que fazem parte do universo dos atores, relatos de mulheres negras moradoras de periferias de Belo Horizonte, evando em conta as suas condições étnicas e socioeconômicas,

bem como os dados apresentados no Mapa da Violência de 2014

2015, que apresentam estatisticamente situações de violência negros.

Anair Patrícia 
Texto de Anair Patrícia, Anderson Ferreira e Andréa Rodrigues

Livremente inspirado na obra Além do rio (MEDEA), de Agostinho Olavo.

\section{INTÉRPRETES}

Anair Patrícia e Anderson Ferreira

PERSONAGENS

Ama

Jinga/Medeia

Jasão (citação)

Ketlin (citação)

Lorraine (citação)

Demais personagens surgidos da interação com a plateia vão pra cena por quebra da quarta parede. Estes personagens podem ser escolhidos durante o samba já chamando o público pelos nomes dos personagens.

Maria

Neide

Seu Pedro

Raiane
Carol

Jackson

\section{CENÁRIO}

Bancadas feitas de caixas de feira pintadas com tons de marrom. No centro, um espelho grande com portas escondendo o reflexo. Na lateral direita, um altar feito com três caixas de feira na vertical com uma ja rra de água, uma vela grossa, um copo de água e suporte para aproximadamente sete velas comuns. $\mathrm{Na}$ lateral esquerda, um rádio, uma cadeira grande e outra cadeira pequena. Há também duas caixas de feira na horizontal, acopladas e com rodinhas.

Os objetos do salão de beleza são organizados nas caixas de feira que depois do Pagode da Ama transformam-se em cômodas e outros suportes do salão que guardam os cremes, os vidros de esmaltes e os demais produtos. 


\section{PRÓLOGO}

(Churrasco, cerveja e música. É o pagode da Ama. O público está se preparando para entrar no quintal da casa da Ama. Ainda em fila, Ama e Jing a conversam com os convidados, oferecem uma bebida, um espeto de churrasco e comentam causos do Morro da Costa d'Ouro: o posto de saúde que não funciona, o abaixo assinado para abertura de uma creche, as desavenças entre vizinhos, a constante intervenção dos policiais e a mortes dos jovens do morro. Entre uma conversa e outra, Ama oferece seus serviços que vão de cartomante a manicure. Aos poucos, as personagens convidam o público para entrar. A festa é uma ação para arrecadar dinheiro para Ama abrir seu salão de beleza. Música alta. Tocam funk, rap e pagode, até que, no ápice da música, da dança e dos diálogos, ouve-se sons de tiros. Jinga sai correndo e Ama, além de tentar controlar a confusão, vai ao seu altar rezar. Acender a vela.)

\section{PRIMEIRO ATO}

AMA (arrumando a casa/salão de beleza) - Jogo búzios, jogo tarô, faço mapa astral e jogo cartas. Faço de tudo um pouco gente, o que foi? Nessa guerra que a gente vive num dá pra dar mole. Aliás, eu trouxe umas coisinhas pra vender pra vocês (pega uma sacola com vários produtos). Coisa de primeira! Olha esse porta-retrato (mostra uma foto da sua mãe). Desde criança eu queria ser assim: linda! Igual mamãe. Mamãe ficou mais bonita foi nesse porta-retrato que é 4,99. Vai levar, Márcia? Ma mãe, minha filha, trabalhava a semana inteira pra sustentar nossa casa. Lavava, passava, cozinhava e no final de semana a nega ainda arrasava no samba, meu amor. Deixa eu ver se esse som tá funcionando. Faço em duas vezes, alguém quer? O, tem uns cremes que chegou numa revista nova, coisa boa, viu Neide? Olha esse cheiro. Ótimo para hidratação. Tô fazendo por trinta reais. Esse pote é grande, qualquer coisa você até divide com a sua mão. Aí cada uma paga quinze reais e fechou. Vai levar? Se não tiver dinheiro agora você paga mês que vem. Ó, não se preocupa, você vai pagando aos poucos. Já vou até anotar aqui no caderninho porque você vai levar e vai adorar, Neide! Fala com ela, Seu Pedro, que aqui é tudo parceria, que a gente ajuda. Esse creme é bom mesmo. Ma mãe usava. Vivia ne ta mbém. Jéssica, Ketlin, Jinga.. Lembra de Jinga, Márcia? (Pega outro objeto para vender) tem coisa aqui que eu não vendo não, porque é da minha proteção. Mas eu tava falando de Jinga, né Seu Pedro? Jinga era rainha aqui neste morro. A Costa d'Ouro nunca mais teve uma liderança de verdade como na época de Jinga. Essa creche aí embaixo que você matriculou seus meninos Neide, foi Jinga quem arrumou. Lembra daquele abaixo assinado, Bruninha? Jinga entregou na prefeitura e eles construíram a creche pras crianças estudarem. Ó, Jinga organizou dias das crianças, conseguiu as doações da festa de erê e teve a té o natal na Costa d'Ouro! (tira um enfeite de natal da sacola Esse papai noel também tô vendendo, viu 
Sueli? Dois reais! Pra qua ndo chegar o natal você não precisar comprar nada naquele xing ling lá de baixo, que só te enrola. Mas como eu tava falando, teve aquela guerra aqui, né? Aí o capitão subiu o morro pra colocar ordem e dar um jeito no pessoal. Só que ele encontrou com Jinga, que em nenhum momento abaixou a cabeça pra ele e defendeu todo mundo. E o capitão, ó, ficou chocado. Resolveu subir o morro todo dia pra ficar de lero-lero com Jinga Aí a nega se apaixonou. Só pensava em amor. Como se a mor enchesse barriga, né Neide? Quer dizer, encheu né? Jinga engravidou. Teve dois meninos. Agora tá lá, no outro lado. Não dá notícia e nem veio me apresentar os meninos. Nem sei como estão. Mas eu tô aqui né gente. A vida segue. Vamos fazer essa unha, Raiane? Posso colocar uns brilhos pra você arrasar no baile, quer? Tá na promoção! Ai, Raiane! Você sente saudade dos meus pagodes? Parei de fazer né? Fiquei aqui sozinha. Quer dizer, tem o Ricardo. Mas ele não para em casa. Aliás, que horas são? (à plateia) Ele e Sheila. Marquei com ela de fazer a sobrancelha, mas você sabe como Sheila é, né? Nunca chega na hora...

(Batem na porta)

AMA - Aí, é só falar na assombração... Entra Sheila!

(Batem na porta mais forte)

AMA - A porta tá aberta, linda! É só entrar...
(Batem mais uma vez)

AMA (levantando-se e abrindo a porta sem parar de falar) - Deixa de ser folgada Sheila... Quer dizer que eu tenho que abrir a porta pra madame...

(Medea/Jinga entra correndo. Parece que está se escondendo interrompe a fala de Ama)

\section{MEDEA/JINGA - Fecha essa porta, fecha!}

(silêncio)

MEDEA/JINGA - Nossa, não aguento mais subir esse morro. É muito pesado. Muita escada, muita viela.

(silêncio)

MEDEA/JINGA - Oi, Ama! Boa tarde.

AMA - Jinga?

MEDEA/JINGA - Medea!

AMA - Medea? Que digina é essa que eu nunca ouvi falar?

MEDEA/JINGA - Não é digina, esse agora é meu nome. Vem do grego...

AMA - Tá toda mudada. 
MEDEA/JINGA - Está tudo diferente por aqui. Chegou lá do outro lado que você tá trabalhando com... é salão de beleza?

AMA - Sim, é daqui que tiro meu sustento.

MEDEA/JINGA - Olha que graça. Que glória!

AMA - Que que foi, hein? Lembrou dos pobres?

MEDEA/JINGA - Eu vim te ajudar, Ama. Vim cortar, alisar e pranchar, quanto custa?

AMA - Meu pai Oxalá, um cabelo tão bonito como esse mulher!

MEDEA/JINGA - Eu não quero mais esses cachos, Ama. Você pode alisar tudo viu? Inclusive a raiz.

AMA - Pois não tem creme alisante que apague nossa raiz, viu... como é mesmo o nome que te deram?

MEDEA/JINGA - Medea! E eu não entendo mais nada de raiz. Só sei que Jasão gosta assim, bem liso, então alisa tudo, inclusive a raiz.

$$
\text { AMA - E desde quando Jinga (...) }
$$

MEDEA/JINGA (Corrigindo) - Medea!

AMA (ironizando) - Desde quando Medeia faz as vontades daquele soldadinho de chumbo?
MEDEA/JINGA - Soldadinho de chumbo não, CAPITÃO!

AMA (Ignora Jinga/Medea e volta ao diálogo com o público) E aí, Raiane? Já secou o strass? Cinco reais, tá?

MEDEA/JINGA (Interrompe) - Você está trabalhando aqui sozinha? Cadê Ketlin? Achei que ela tava te ajudando.

AMA - Ketlin agora tá estudando.

MEDEA/JINGA - Estudando? Que curso? Magistério?

AMA - Não, faculdade! Tá estuda ndo pra ser advogada!

MEDEA/JINGA - E como ela está pagando? Fazendo unha?

AMA - Não tá pagando, não. Porque entrou numa universidade pública. E a menina é tão boa aluna que já tá trabalhando num escritório lá no centro. Lá do outro lado.

MEDEA/JINGA - Hum...Daqui uns dias ela sai do morro também.

AMA - Pode até sair. Mas ela não vai fazer igual umas e outras que fugiu e esqueceu do povo.

MEDEA/JINGA - Ai, Ama! Misericórdia! Você pode alisar meu cabelo ainda? 
AMA - Não tenho mais horário hoje. (volta-se para o público) Aliás você já decidiu se vai pintar esse cabelo, Ca rol? Tira o pé do meu almoço minha filha, isso aqui tá lotado hoje.

MEDEA/JINGA - Quanto esse povo ia pagar? Eu pago o triplo!

AMA - Posso a té rever meus horários. Mas não aceito cartão, tá?

MEDEA/JINGA - É só me falar o preço, Ama. Eu pago em dinheiro vivo. Pode escolher entre euro, dólar, real..

AMA - Eu gosto é assim. (Pega o telefone/celular liga pra Gleice ou manda áudio) Gleice, vem outro dia tá. Tenho que resolver uns problemas aqui. (Voltando-se para Jinga/Medea)

Vou atender a madame. Mas me conta aqui, onde você consegue esse dinheiro? Cartas e búzios não deve ser, porque deixou tudo aqui.

Ama puxa a cadeira para que Jinga/Medea se sente, organiza-a na cadeira e coloca a toalha em volta de seu pescoço. puxa a banca de produtos de cabelo para perto. O diálogo ocorre simultaneamente à ação.

MEDEA/JINGA - Não ficou sabendo não?

AMA - Não.
MEDEA/JINGA — Porque não é da sua conta!

AMA - Ai horrorosa! Deixa eu ver então o que tá acontecendo: a menina vem aqui na minha casa sem avisar ainda é mal-educada, mas deixa, o que é dela tá guardado (abre o cabelo de Jinga/Medeia fazendo alusão ao processo de raspagem da cabeça no candomblé, olhando entre os cabelos) Jasão por um acaso sabe que Medea é filha de Iansã?

MEDEA/JINGA - (Desvencilhando-se de Ama, mas ainda sentada na cadeira) Cala a boca, língua de cobra maldita! Não sou filha de Iansã nenhuma. Agora eu sou batizada! E não mexe no meu cabelo não, tá?! Quer dizer, começa pela unha, faz só minha unha.

AMA - Do jeito que a cliente preferir. Ó, chegou uma coleção nova de esmalte que eu comprei na revista. Coisa nova. Essa revista tá boa, viu? Dá uma olhadinha... os produtos chegam no mês que vem. (Pra pessoa da plateia) Quer olhar também, Carol? (Voltando-se para Jinga/Medea) Mas tem que vir buscar viu, não entrego fora do morro não. Deixa eu ver essas unhas. Tá bom não mulher, vou dar um jeito tá? A gente passa um esmalte café, ou um vermelho bordô, vermelho sangue você gosta mais, né?

MEDEA/JINGA - Tá louca? Vermelho não!

AMA — Ué, por quê? 
MEDEA/JINGA - Muito cha mativo. Passa um mais discreto. Um mais clarinho, um renda..

AMA - Meu pai Oxalá, tá aí, Jinga com branco na mão MEDEA/JINGA - Medea! Pode passar branco. É mais elega nte, mais chique. Dá um ar de limpo, um ar angelical, né? Combina mais comigo hoje. O Jasão é que fala.

AMA - (Interrompendo) Ó, coloca essa mão de molho logo que eu não tenho o dia todo.

(som de bombinhas)

MEDEA/JINGA - Que isso, Ama?

AMA - (Gritando de dentro do salão em direção a porta por onde Jinga/Medea entrou) Ô Lorraine! Você não dá educação pros seus filhos não, minha filha? Tô com visita em casa e esses meninos ficam jogando bombinha na porta dos outros...

MEDEA/JINGA - Não fala que eu tô aqui não!

AMA - Esses meninos de Lorraine são uns demônios Meu pai oxalá! (Se levanta e vai em direção ao altar de Ama e acende uma vela)

MEDEA/JINGA - Achei que era tiro...não tô acostumada com tanto barulho assim.
AMA - Ah, não tá, não? Aqui é assim todo dia. Vai, põe a mão nessa água logo porque eu não tenho o dia todo.

(som de tiro)

MEDEA/JINGA - Que isso, Ama?

AMA - É tiro né mulher! Até parece que esqueceu da vida que a gente leva aqui.

MEDEA/JINGA - Meu pai Oxalá!

AMA - Na hora do aperto a té chama né?

MEDEA/JINGA - Ai, Ama, quem será dessa vez? Ainda bem que eu não trouxe os meninos...

AMA - Ah!!! O Ricardo! Ele fica zanzando de moto pra cima e pra baixo nesse morro. E o zome tão aqui fazendo um pente fino desde semana passada. Ô Lorraine (Para fora da porta), quem foi dessa vez? Você viu Ricardo por aí? Não? Aiii. Fica dentro de casa viu? A bala tá comendo solta MEDEA/JINGA - Vaso ruim não quebra, Ama.

AMA - Mas eu sou capaz de ir lá embaixo pegar esse Ricardo... ah se eu vou!

MEDEA/JINGA - E eu vou ficar aqui sozinha?

AMA - Então vai comigo 
MEDEA/JINGA - Tá louca? Sossega o facho aí que notícia ruim chega logo.

AMA - O morro tá em guerra, Jinga. Semana passada foi Jhonatan.

MEDEA/JINGA - Jonathan filho de Janaína?

AMA - Aham

MEDEA/JINGA - Coitada de Janaina!

AMA - O menino era bom, viu? Passava aqui em casa, cumprimentava... Ah! E teve Duda!

MEDEA/JINGA - Maria Eduarda filha de Rosilene?

AMA - Rosilene ficou destruída! Aliás, faz tempo que eu não vejo Rosilene. Você tem notícias dela, Gleice? Porque foi uma atrás da outra, né? Teve aquela menina lá, a sapatão que morava ali embaixo.

Jinga/Medea se levanta em direção ao altar de Ama e vai acendendo as velas uma a uma, à medida que vai dizendo os nomes. A cena ocorre em dois planos, Ama em diálogo com o público, sentada na cadeira e Jinga/Medea ao fundo dizendo os nomes de jovens negros assassinados em voz alta na medida em que acende as velas.

MEDEA/JINGA - Luana Barbosa
AMA - Isso, Carol. Ela tinha acabado de se formar, né?

MEDEA/JINGA - (São colocados os nomes de pessoas negra assassinadas

AMA - Isso! teve (...) ta mbém...e aquele outro lá?

MEDEA/JINGA - (Nome)

AMA - Teve mais ta mbém, não teve? Só esse ano foram quantos, hein, Carol?

MEDEA/JINGA - (Mais nomes, é importante dizer o nome completo de todos)

AMA - É minha filha, a coisa tá feia... (Olha pra trás em busca de Jinga/Medeia ) que que foi, mulher? Ó, vamos tomar uma cerveja, ouvir uma música pra tirar esse nó na garganta. Quer uma?

MEDEA/JINGA - Não. Não bebo!

AMA - Hum... Então toma você, (entrega a alguém da plateia)! Um brinde a nós, que estamos vivos!

MEDEA/JINGA - Por enquanto...

AMA - Nossa, semana que vem vai ter festa de Iansã lá no terreiro.

MEDEA/JINGA - Macumba? Já falei que eu sou batizada! 
AMA - Macumba sim, horrorosa. Ó, põe essa mão de molho logo. (entregando novamente a bacia)

MEDEA/JINGA - Mas quem vai fazer o aca rajé?

AMA - Tânia...

MEDEA/JINGA - E desde de quando Taninha faz um aca rajé gostoso?

AMA - Desde quando você não vem fazer.

MEDEA/JINGA - Agora eu sou batizada, Ama. Mulher de capitão! Sou mãe!

$$
\text { AMA - Ah! E os meninos, como estão? }
$$$$
\text { MEDEA/JINGA — Lindos! }
$$

AMA - Lindos...Que dia você vai trazer eles aqui? Pra eu ver, brincar aqui no quintal?

MEDEA/JINGA - Nesse lugar? Com esse tipo de gente?

AMA - Minha casa, tá?

MEDEA/JINGA - Jamais! Prometi a Jasão que aqui eles não colocariam o pé nunca.

AMA - "Prometi a Jasão", aí vai deixar os menino preso lá no condomínio. Na mansão da senhora Jasão. Senhora
Jasão não né, linda? Acho que nem te apresentou pra família ainda.

MEDEA/JINGA - Vai cuidar da sua vida!

(Ama belisca Jinga com o alicate)

MEDEA/JINGA - Ai!

AMA - Doeu? Dá um gole nessa cerveja que passa.

MEDEA/JINGA - Que insistência. Já falei que eu não bebo! Que sou mãe, mulher de capitão e desliga esse rádio! AMA - Gente! Que que foi que o rádio fez?

MEDEA/JINGA - Essas músicas melosas, chatas, falando de paixão e lálálá, lêlêlê...

AMA - Hum...tá nervosa? O branquinho não comparece, não? Pode falar.

MEDEA/JINGA - Ridícula! Comparecer, comparece. Mas tá viajando faz dez dias. Não atende telefone, não liga. E vai ter uma festa pra gente ir no condomínio. O noivado de uma ricaça lá e cadê ele?

AMA - Ah sim...por isso esse alisa alisa todo, né, mulher? (Mais pra si do que exatamente pra Jinga/Medea)

MEDEA/JINGA - E você acredita que ela não me convidou? 
AMA - Como assim? Não convidaram a mulher de Jasão?

MEDEA/JINGA - Mas vão se a rrepender, porque eu vou chegar arrasando: lisa e loura!

AMA - Aham, lisa...

MEDEA/JINGA - Sabe que eu tô com uma pulga atrás da orelha com essa história? (Se levanta da cadeira, inquieta)

AMA - Ai mulher, esse povo rico é assim mesmo, não convidam as pessoas por motivos bobos. E é capaz de você ser a última a saber porque não te convidaram...

MEDEA/JINGA - Você tá vendo alguma coisa aí, Ama?

AMA - Não tô vendo nada!

MEDEA/JINGA - E nem tá sabendo de algum disse me disse, trelêlê, fofoquinha.

AMA - Eu não sei de nada.

MEDEA/JINGA - Mas não é a Ama que sabe de tudo que acontece nesse Morro?

AMA - É né a mor, só que no Morro!

MEDEA/JINGA - Você sabe que é só eu cantar um ponto pra colocar um feitiço nesse seu cu, né?
AMA - Para, ridícula! (Diz sentando na cadeira e abrindo a bolsa de Jinga/Medea. Brincando com a bolsa e os óculos escuros de dentro da bolsa) Agora eu tô bonita mesmo, né? Você acha que eu vou sair da minha casinha pra saber de coisa lá do seu condomínio, pra eu ser parada, ter de aturar aquelas madame me olhando torto. Me reparando de cima a baixo, olhando as minhas roupas, falando de como eu me visto... mal sabendo elas que os homens tudo casado comem é aqui ó, da carne da bicha favelada. Aí tu acha que eu vou sair da minha casa pra isso? Me respeita, minha filha.

MEDEA/JINGA - Ficou nervosa? Ricardo não tá comparecendo não? Agora me dá essas coisa porque isso é caro e você não sabe usar não.

AMA - Horrorosa, ele sumiu.

MEDEA/JINGA - De novo? Deve ter voltado pra Fátima.

AMA - Voltou não! Só vai lá pra pagar a pensão do menino dele.

MEDEA/JINGA - Com que dinheiro, Ama? Você ainda tá sustentando o malandro do Ricardo?

AMA - Ele faz os "corre" dele, Jinga. Todo mundo hoje faz "corre".

MEDEA/JINGA. Medea! Sei que "corre" ele faz... Olha, não concordo, viu? Não te assume, só vem aqui fazer 
gracinha, pegar seu dinheiro e vai embora. Mas você não me ouve.

AMA - Você podia me ensinar uma coisa pra a marrar ele aqui em casa, lá no terreiro não tem quem dê jeito!

MEDEA/JINGA - Não consigo a marrar nem o meu, Ama...

AMA - Lógico! Com essas roupas feias. Agora eu posso falar, né? Tá bom não, quem fez esse figurino pra você ir se confessar, hein?

MEDEA/JINGA - É roupa chique! Cara! Você não entende nada!

AMA - Mas é feia! É só pra tirar foto, né? Porque olha...

MEDEA/JINGA - Agora eu sou mulher de capitão. Tenho que me comportar. Estar sempre apresentável, ser bem educada, falar baixo e só responder quando eu for perguntada. Tenho que ser discreta, quase invisível. No lado de lá as coisas são assim: acontecem de outro jeito. A gente parece ser outra pessoa. Tem que tomar cuidado com o que fala, com o que veste. Mesmo assim eles não tiram o olho e ainda cochicham "a lá a negra fedida", "feiticeira" "preguiçosa”, "macumbeira”. Só gostam da nossa bunda, do nosso peito, do nosso tempero... querem nos comer. Comer, comer, comer e depois você fica lá sozinha, Ama.
(Jinga/Medea se excede no desabafo, foge ainda mais da persona que sustentava desde o início, quando cai em si novamente Ama está assustada olha pra ela) Que foi? (se recompondo, mas não mais voltando à persona como antes).

\section{SEGUNDO ATO}

AMA - Olha mulher, se eu fosse você colocava os búzios na mesa. Você não pode ficar nessa situação, não.

MEDEA/JINGA - Você tá sabendo de alguma coisa que eu não sei, Ama?

AMA - Eu não sei de nada.

MEDEA/JINGA - Algum disse-me-disse? Trelele? Fofoquinha? (Encurralando Ama, que desvencilha)

AMA - Já falei que eu não sei de nada!

MEDEA/JINGA - Pois eu já sei quem deve tá fazendo fofoca com meu nome. (Medea/Jinga abre a porta e grita) Ô Lorraine! Você não tá inventando conversa fiada com meu nome não, tá? Toma jeito viu, Lorraine! Não quero meu nome na boca de cachorro, não.

AMA - Tá louca? (Fechando a porta que Ama abriu) Deixa Lorraine fora disso

MEDEA/JINGA - Abre os búzios pra mim! 
AMA - O quê?

MEDEA/JINGA - Joga os búzios pra mim, Ama!

AMA - Você tem certeza, mulher?

JINGA/MEDEA - Tenho! Abre logo esse jogo! (Indo para o espelho onde Ama joga búzios)

AMA - O soldado que subiu morro com morte nas mãos desce com Jinga nos braços. Peito a rmado, o bra nco levou a negra de seu lugar com balas, ferro quente, tapas e correntes, Jinga esqueceu nome, família, história. Nasce Medea! Vejo a rainha do tempo chorando por sua filha, vejo raio rasgar o céu como um grito e a ventania espalhar tudo, vejo branco tentando juntar história com a mão errada Vejo dor enraizada. Vejo machucado ardendo quando o suor bater. Vejo a festa dos senhores, a festa do casamento, a casa grande, o condomínio. Vejo a rainha da roda girar. Volta Jinga, deixa Medea! Volta pro que é teu, toma tua espada de volta e volta. O que te fez morrer, também vai te fazer voltar. É o fim de Medea e Jasão!

JINGA/MEDEA - Mentira! Olha isso direito...

AMA - Jasão está se casando com a branca.

JINGA/MEDEA - Mentira, Ama!
AMA - Jasão está se casando com a ricaça lá! Todo mundo já sabe...

JINGA/MEDEA - Você já sabia né, Ama! Lógico que você sabia! Todo mundo sabia. Você tava aí, ó. Ai, desgraçado! Desgraçado! Ele me paga! Ama, ele falava que me a mava! Que ia colocar uma aliança na minha mão, que eu ia entrar na igreja, que ia me apresentar pra todo mundo... Desgraçado! Desgraçado! Mas ele acha que vai sair por cima? Que vai me trair e vai sair como o bambambam? Ficar fazendo festinha com aquela ricaça... desgraçado! Mas não vai é mesmo! Porque ele tá achando que tá mexendo com quem? Eu jurei a mor, eu jurei amor e parei de amar, eu acreditei Ama, eu acreditei! Eu fiz tudo certo, eu não dancei, eu não questionei, eu estava lá, eu era o que era pra ser, eu fui Medea, agora acabou! Eu sou Jinga! Da costa do ouro! Tá pensando o que? Desgraçado! Não vai ficar assim. Vai ter volta! Porque eu mato!

AMA - Matar o quê? Não vai matar ninguém, mulher! Calma!

JINGA/MEDEA - Eu mato!

AMA - Seu coração tá cheio de ódio, de raiva! Calma! Pensa com calma. Não faz nada de cabeça quente. Porque ainda tem os meninos.

JINGA/MEDEA — Os meninos...os filhos de Jasão! 


$$
\text { AMA - É, mulher! }
$$

JINGA/MEDEA - Ama, vai lá no açougue da Rose e traz..

AMA - Eu não vou!

JINGA/MEDEA - Ama! Vai no açougue e traz aquela carne.

$$
\text { AMA - Não vou, não vou, não vou! }
$$

JINGA/MEDEA - Traz a carne, meus temperos e minha água!

AMA - Não vou sair daqui!

\section{JINGA/MEDEA — Ama!}

AMA - Mulher, pra que tudo isso? Você já foi tão feliz, quando nos seus brinquedos no morro, nas suas risadas alegres e nas danças de terreiros, não sabia o que era a mor. E os moços daqui tudo saiam atrás de você. $O$ coração da rainha não tinha dono nem amor. Você era feliz assim. Maldita! Maldita a hora em que Jasão subiu aqui. Maldita! Agora tá aí ela que não cabe nela. Essa menina não nega a mãe que tem, essa mulher é filha da tempestade; pra me fazer uma bobagem não custa. Jinga, calma! Deixa isso! Vida nova.

JINGA/MEDEA - Ama, pega a carne!

\section{AMA - Tá! Inferno!}

Ama sai e volta com a bacia com fígado e as ervas de cheiro pro temperar: alecrim, manjericão roxo.

AMA - Jinga, minha rainha! Ainda dá tempo. Você era tão feliz quando não sabia o que era o amor...

Jinga dá o texto temperando a carne, sem tirar os olhos do processo.

JINGA/MEDEA - Amor? Que amor, Ama? Esse povo só gosta mesmo é de comer. E se a carne tiver dura eles ainda batem! Batem com pau, chicote, pedra... pra carne ficar bem macia. E se não der certo eles furam. Furam ela bem furadinha que é pro tempero entrar melhor. Tá vendo? Eles gosta m dela assim ó: sangrando. Só que dessa vez não, dessa vez eles é que vão experimentar as mandingas que eles mesmo me proibiram de fazer. Agora você vai lá, Ama. Vai no noivado. Vai entregar essa carne pra Creusa, pra noiva! Depois você vai passar no condomínio e vai pegar os meninos pra mim. Eu quero eles aqui do meu lado!

Jinga entrega a bacia com a carne temperada para Ama e depois troca de roupa durante a música "Samba, minha raiz" enquanto Ama busca "os meninos" no condomínio. 
O SAMBA REINOU

A NOITE INTEIRA DE UMA TAL MANEIRA

QUE ESPANTOU A TRISTEZA

PROVANDO QUE O SAMBA DE RACA TEM FORCA E PUREZA

QUEM SAMBA PARTIDO ALTO SAMBA MIUDINHO

O FAZ COM AMOR E CARINHO

O CORPO SE LIBERTANDO

GINGA NA CADÊNCIA QUE É VIDA!

APESAR DE TÃO SOFRIDA

FAZ O MAL SE AFASTAR

AH! COMO A GENTE OFERECE

TUDO QUE VIVE A SONHAR

GINGA NA CADÊNCIA QUE É VIDA.

APESAR DE TÃO SOFRIDA

FAZ O MAL SE AFASTAR

E TODA GENTE FELIZ CANTAR

AI MEU DEUS...

COMO AGRADEÇO POR NASCER

O SAMBA É MINHA RAIZ,

MINHA HERANÇA MEU VIVER

ME CONSOLA A BELEZA

QUE NINGUÉM DESEJA ACHAR

ME GUIA NA MINHA INCERTEZA

\section{NÄO ME DEIXA TROPECAR}

O SAMBA...

(Samba, minha raiz - Ivone Lara)

\section{JINGA/MEDEA - Trouxe os meninos, Ama?}

Ama entra com duas cadeiras pequenas simbolizando os meninos, entrega-as a Jinga/Medea.

JINGA/MEDEA (para o público) - Eles que são dois punhais enfiados a força por entre minhas pernas, o grito do nascimento mulato! O choro abafado, tampado, calada! São nascidos da minha dor, a morte da minha voz. O sangue escorrido das minhas costas, e o nojo de ter minha pele agarrada, penetrada, clareada. Eles que marca ra $\mathrm{m}$ com ferro quente minhas costas e meus cabelos. Eles que calaram meu canto e sufocaram a minha dança. Eles que sugaram meu leite, que me fizeram reprodutora, procriadora, preta fértil, safada! Come, manda, bate que ela aguenta. Preta é forte! Eles que são filhos da mistura da dor, do ódio... o que me fez morrer. E agora vai me fazer voltar!

AMA (Acendendo duas velas pela morte dos meninos canta) Deixo a chuva que derruba o céu, lavar. Lavo a carne que ainda tem no osso. Sinto o osso antes dele se quebrar. Abro a tampa e deixo a dança entrar no corpo. 


\section{EPILOGO}

JINGA - Adivinha quem chegou?

AMA - Quem?

JINGA - Seu Pedro!

AMA - Então vai logo pegar uma cerveja pro Seu Pedro! Seu Pedro, fica à vontade, viu? Com tempo a gente vai colocando tudo em ordem de novo. Jinga agora tá aí. Jinga demora não, minha filha! Ei, Sheila! Apareceu, né sumida? JINGA - Olha a cerveja gelada chegando! Quem vai querer? Cinco reais...

(Atores saem vendendo cervejas até se dispersarem pela plateia)

FIM. 